\title{
Clinical Image
}

\section{Caroli's Disease:A premalignant condition?}

\author{
Sabrina Rahman, ${ }^{1}$ S K Jakaria Been Sayeed, ${ }^{2}$ Mostofa Kamal Chowdhury ${ }^{3}$
}

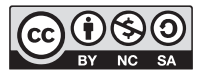

DOI: http://dx.doi.org/l0.3329/jom.v20il. 38865

Copyright: (C) 2019 Rahman $S$ et al. This is an open access article published under the Creative Commons Attribution-NonCommercial-NoDerivatives 4.0 International License, which permits use, distribution and reproduction in any medium, provided the original work is properly cited, is not changed in any way and it is not used for commercial purposes.

Received: 09 November, 2018;

Accepted: 29 November, 2018

A 29-Year-Old male presented with recurrent history of upper abdominal pain, fever $\&$ jaundice for last five years. He was icteric, had hepatosplenomegaly. However, rest of the clinical examinations revealed no abnormality. His liver enzymes were raised. All viral markers were found negative. Endoscopy upper GIT revealed no abnormality. His Ultrasound abdomen (Figure a,b) also revealed hepatomegaly with inhomogeneous parenchyma, multiple cysts along the intra hepatic biliary channel especially in right lobe with evidence of cholangitis and mild splenomegaly. Both kidney \& CBD appeared normal. He was diagnosed with caroli's syndrome on the basis of magnetic resonance cholangiopancreatography (MRCP)

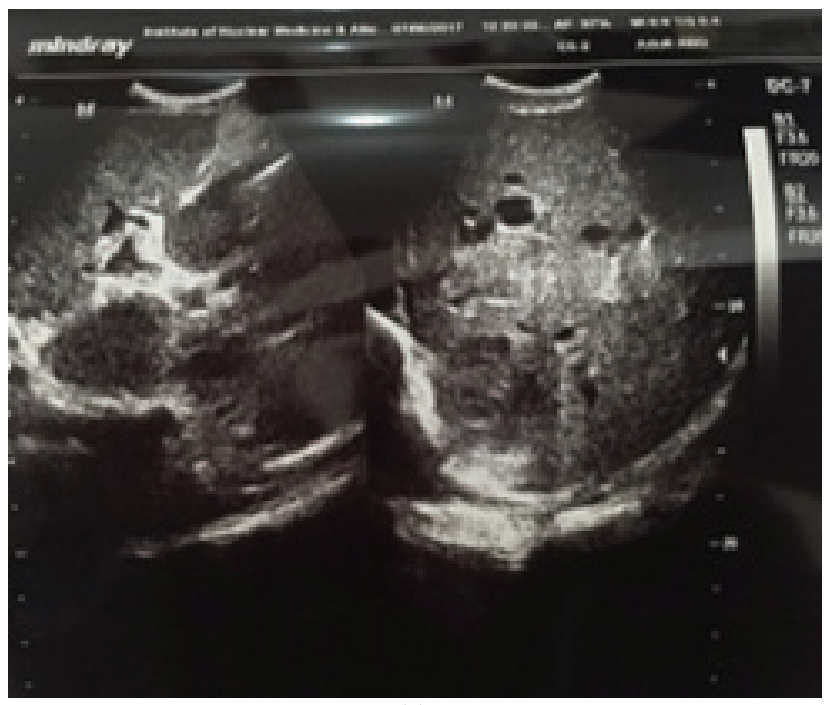

(a)
(Figure c, d). We did FNAC from cystic lesion that revealed only hepatocyte, definitely ruled out malignancy.

Caroli's disease is a rare congenital disorder characterized by segmental, non-obstructive dilatation of intrahepatic bile ducts. The term Carolis syndrome is used for the association of Caroli disease with congenital hepatic fibrosis. ${ }^{1}$ It may manifests as noncirrhotic portal hypertension, recurrent cholangitis \& even cholangiocarcinoma. ${ }^{1}$ The central dot sign, defined in the literature as a dot or bundle of strong contrast enhancement within dilated intrahepatic ducts, found in MRCP is highly specific for the disease. ${ }^{2}$ The definitive treatment for Carolis syndrome requires liver transplantation for diffuse disease and hepatic lobectomy for isolated lobar disease.

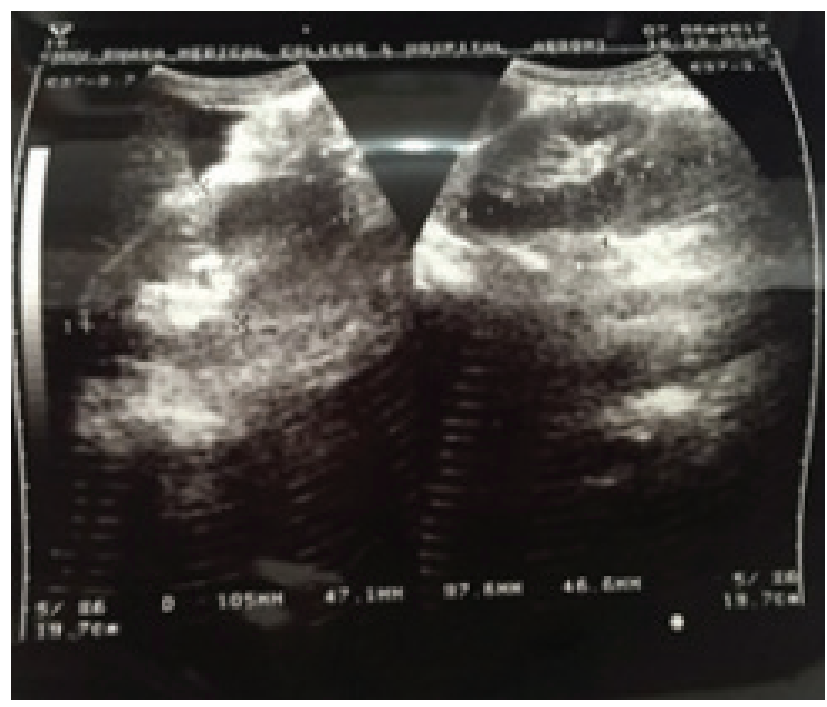

(b)

Figure: (a) USG showing hepatomegaly with multiple cysts in right lobe of liver; (b) normal kidney (no cyst);

1. Post graduate trainee, Dept. of Medicine, Dhaka Medical College Hospital.

2. Indoor Medical Officer, Dept. of Medicine, Dhaka Medical College Hospital.

3. Assistant Registrar, Dept. of Endocrinology, Dhaka Medical College Hospital.

Corresponding author: Dr. S K Jakaria Been Sayeed, Indoor Medical Officer, Dept. of Medicine, Dhaka Medical College Hospital. Email: skjakarial@gmail.com. 


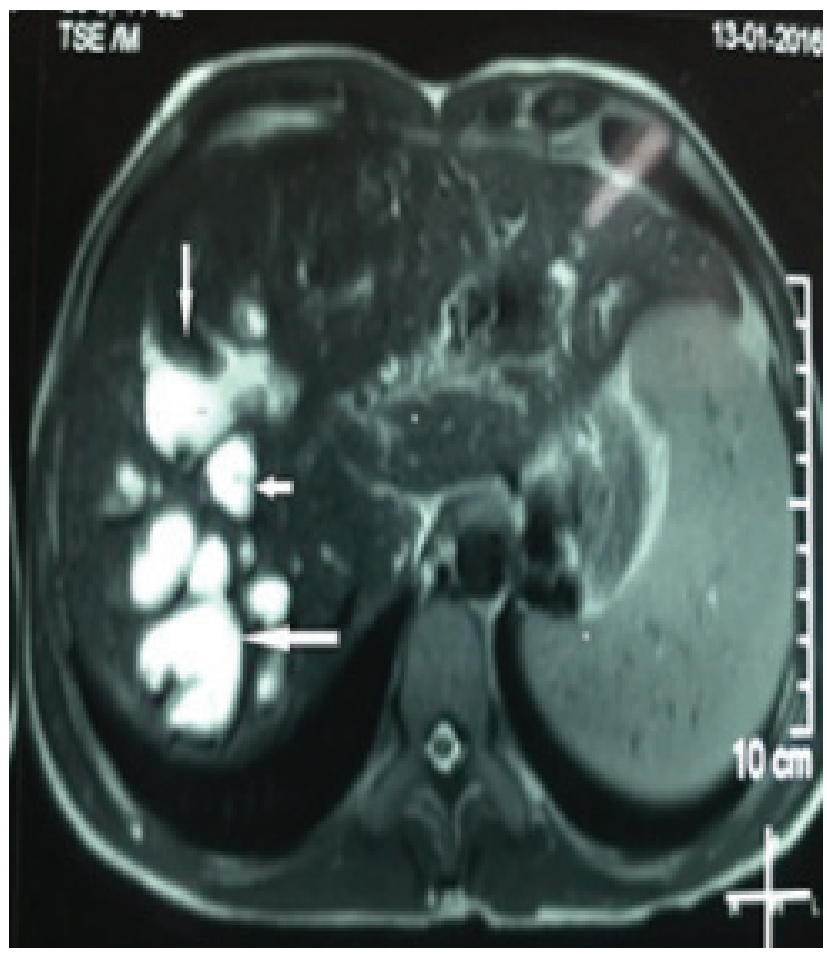

(c)

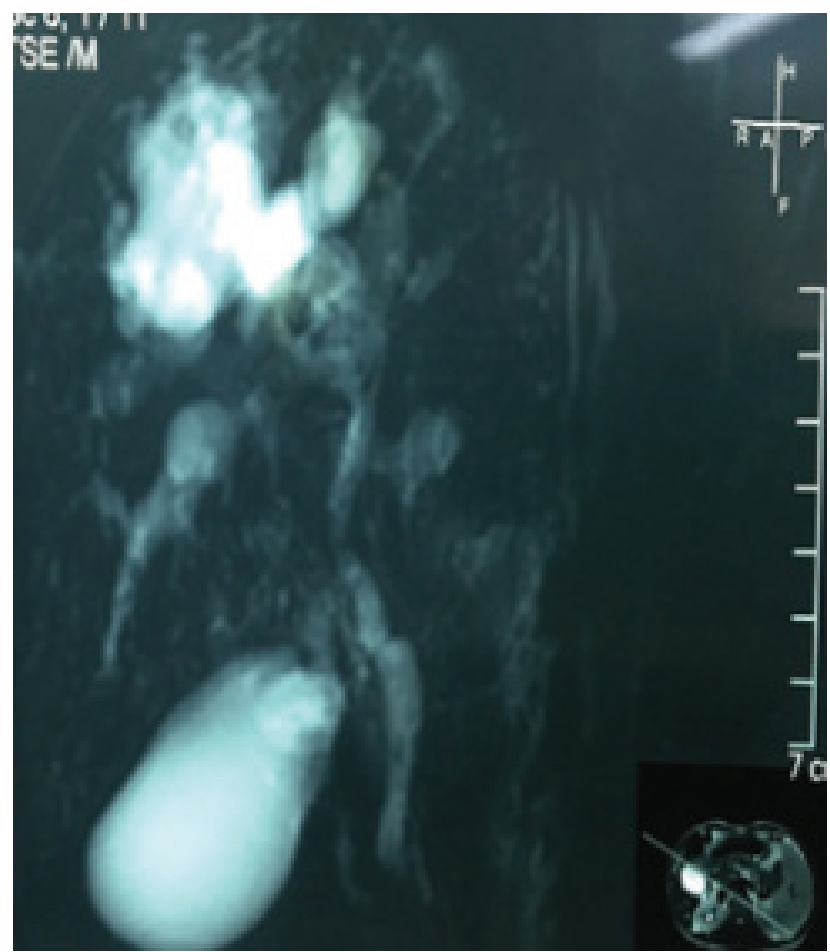

(d)

Figure: (c) MRCP showing multiple intrahepatic cystic dilatation of biliary tree with tiny signal void area (central dot sign)(white arrow), splenomegaly; (d) MRCP showing normal extra-hepatic biliary tree, gall bladder common bile duct and main pancreatic duct.

\section{References:}

1. Desmet VJ. Congenital diseases of intrahepatic bile ducts: variations on the theme 'ductal plate malformation'. Hepatology 1992;16:1069-1083. https://doi.org/10.1002/hep.1840160434

2. Choi BI, Yeon KM, Kim SH, Han MC. Caroli disease: central dot sign in CT. Radiology 1990;174:161-163. https://doi.org/10.1148/ radiology.174.1.2294544 